\title{
Некоторые особенности допроса в суде с участием присяжных заседателей с точки зрения юрислингвистики
}

\author{
Е.Г. Зейдлиц \\ Российский государственный университет правосудия, Северо-Западный филиал \\ 91014, Санкт-Петербург, ул. Чехова, д. 8, кв. 14. E-mail: zeidlits@yandex.ru
}

\begin{abstract}
В статье обосновывается необходимость уяснения положений уголовно-процессуального закона с точки зрения юрислингвистики, а также адаптации правовых терминов и действий для обычных граждан, которыми являются присяжные заседатели, в том числе при постановке вопросов при допросе и для вынесения вердикта.

Для решения этой проблемы предлагается обеспечить сочетание дискреционных полномочий судьи по формулированию вопросов с предоставлением сторонам возможности ознакомления с письменными вопросами присяжных заседателей, а также возможности возражения в случае необоснованного их отведения председательствующим судьей. Кроме того, требуется уточнение требований к содержанию напутственного слова председательствующего и предоставление присяжным заседателям решения единственного вопроса о виновности либо невиновности подсудимого.
\end{abstract}

Ключевые слова: присяжные заседатели, допрос, уголовный процесс, юрислингвистика.

LEGAL COMMUNICATION

\section{Some features of interrogation in trial jury according to legal linguistics}

\author{
Zeidlits E.G. \\ Russian State University of Justice; North-West Branch \\ 191014, Saint Petersburg, Chekhova St. 8-14. E-mail: zeidlits@yandex.ru
}

\begin{abstract}
The article discusses the necessity of understanding the provisions of the criminal procedure law from the point of view of legal linguistics, as well as the adaptation of legal terms and actions, including the formulation of questions during interrogation and for the verdict, for ordinary citizens, who may act as jurors.

To solve this problem, it is proposed to ensure a combination of discretionary powers of the judge to formulate questions with giving the parties the opportunity to familiarize themselves with the written questions of jurors, as well as the possibility of objection in case of unjustified exclusion of these by the presiding judge. In addition, it is necessary to clarify of the requirements to the content of the instruction given by the presiding judge and addressing the assizers the only question about the guilt or innocence of the defendant.
\end{abstract}

Key words: assizers, interrogation, criminal court proceeding, legal linguistics.

Как известно, суды присяжных в России имеют непростую историю. Первые суды присяжных в Царской России открылись в 1866 году, в соответствии с Судебными Уставами 1864 года распространили свою деятельность только на 10 губерний центральной России, причина - недостаток квалифицированных юристов для создания общих 
судов в каждом уезде [Казанцев 1991: 12]. Поэтапное распространение судов присяжных в Царской России до всей территории не было доведено, и в 1917 году суды присяжных были упразднены (Декрет СНК РСФСР «О суде» №1 от 24 ноября 1917 года). В Российской Федерации суд присяжных вводился поэтапно с 1 ноября 1993 года, и в отличие от Царской России распространен на всей территории страны. Кроме того, с 1 июня 2018 года суд с участием присяжных заседателей введен и действует не только в областных, краевых, городских и приравненных к ним судах, но и в районных судах, гарнизонных военных судах (Федеральный закон от 23.06.2016 № 190-Ф3 «О внесении изменений в Уголовно-процессуальный кодекс Российской Федерации в связи с расширением применения института присяжных заседателей»).

Исполнилось ровно 25 лет с момента проведения первого в истории послереволюционной России судебного процесса с участием присяжных заседателей, который состоялся 15-17 декабря 1993 года в Саратовском областном суде [Первый..., URL]. С того времени положения закона о рассмотрении уголовных дел с участием присяжных заседателей претерпели значительные изменения. Так, первоначально правовое регулирование обеспечивалось специальным разделом (Х) УПК РСФСР (Закон РФ от 16.07.1993 № 5451-1 «О внесении изменений и дополнений в Закон РСФСР «О судоустройстве РСФСР», Уголовно-процессуальный кодекс РСФСР, Уголовный кодекс РСФСР и Кодекс РСФСР об административных правонарушениях»). С 2002 года действуют положения главы 42 УПК РФ «Производство по уголовным делам, рассматриваемым судом с участием присяжных заседателей» и, к сожалению, нельзя с уверенностью сказать, что изменения положений закона о судопроизводстве с участием присяжных заседателей привели к совершенствованию суда присяжных.

Первые годы возрождения суда присяжных в России сопровождались изданием Летописи суда присяжных (прецедентов и фактов), в которой отражались отчеты обо всех процессах с участием присяжных заседателей в Ивановском, Московском, Рязанском, Ростовском, Саратовском и Ульяновском областных судах, а также в Ставропольском, Алтайском и Краснодарском краевых судах, что позволяло наиболее полно освещать деятельность созданных судов присяжных. Это обеспечивало наибольшую законность и демократичность рассмотрения дел с участием присяжных заседателей, по сути, повторяя исторический опыт Царской России, ранний период развития суда присяжных и всей пореформенной судебной системы [Казанцев 1991: 18].

Стоит отметить, что рассмотрение дел судом с участием присяжных заседателей во многом отличается от традиционного уголовного судопроизводства. Это требует от каждого участника такого процесса тщательной подготовки с учетом использования на каждой стадии судопроизводства юридических терминов и их объяснения присяжным, не обладающим профессиональными юридическими знаниями.

Одним из таких юридически важных действий является допрос в судебном следствии. В данной работе хотелось бы остановиться на особенностях его проведения при рассмотрении уголовного дела судом с участием присяжных заседателей с точки зрения юрислингвистики. В частности, представляется необходимым рассмотреть особенности участия присяжных заседателей в допросе свидетелей, потерпевших, экспертов и других участников судебного разбирательства. Заслуживает внимания и вопрос представления результатов допросов указанных лиц в напутственном слове, с которым профессиональный судья обращается к присяжным заседателям. Также вызывает интерес вопрос о пределах и способах осуществления дискреционных полномочий профессионального судьи при постановке вопросов перед присяжными заседателями.

К числу задач настоящей работы не относится задача показать результат допроса свидетелей и других лиц с точки зрения его значения для представления наиболее четкой информации о событии преступления, или для установления достоверных фактов по делу, а также для подтверждения либо ослабления позиции обвинения или защиты. Результат допроса свидетелей и других лиц помогает в некоторых случаях выявить и показать присяжным ложность чьих-либо показаний, которые нередко влияют на результат дела.

При этом вывод о ложности чьих-либо показаний зачастую невозможен без всестороннего исследования сведений о допрашиваемом лице. Как правило, имеющихся сведений о возрасте, образовании и профессии бывает недостаточно для составления психологического портрета, хотя данная информация и становится предметом для размышления. В связи с этим одной из ключевых проблем в суде с участием присяжных заседателей является решение вопроса о допустимости или недопустимости исследования данных о личности свидетелей и потерпевших. В некоторых случаях полная информация может подорвать доверие к их непосредственным показаниям, т.е. повлиять на оценку достоверности этих показаний. При этом оценка достоверности показаний относится исключительно к компетенции присяжных заседателей. Более того, возникает проблема выяснения в присутствии присяжных заседателей причин дачи различных, с существенными расхождениями, показаний на предварительном следствии и в суде при непосредственном допросе.

Известно, что личное присутствие допрашиваемого обеспечивает восприятие и формирование выводов не только на основе содержания произнесенных им вслух слов, но и с учетом иных форм подачи материала - его внешнего вида, пауз, жестов, дикции и т.п. Напомним, что в суде с участием присяжных заседателей крайне важно тактически правильно не только задавать вопросы, но и направить рассказ допрашиваемого по определенному руслу для выяснения наиболее важных фактических обстоятельств дела. Большое значение, как представляется, имеет установление психологического контакта при допросе между тем, кто ведет допрос, и допрашиваемым лицом. Результат рассмотрения уголовного дела судом с участием присяжных заседателей в большой мере будет зависеть от уровня развития навыка судебного речеведения у профессиональных участников процесса (в первую очередь, судьи, государственного обвинителя, защитника). 
С точки зрения оценки продуктов речевой деятельности в судебном разбирательстве интерес представляет не только содержательная сторона (информация, зафиксированная в речевом сообщении, тексте), имеющая значение для правильного разрешения дела, но и формальная сторона, отражающая языковую, функциональностилистическую, индивидуально-речевую характеристику текста. Таким образом, важнейшим источником доказательств в судопроизводстве выступают результаты речевой деятельности в виде речевых произведений (текстов, фонограмм, переговоров, сообщений, документов), фиксирующие те или иные сведения о фактах, имеющие значение для правильного разрешения конкретного уголовного дела [Галяшина 2015: 38-40].

Стоит отметить, что судебное следствие, в широком смысле слова, представляет собой закономерное продолжение предварительного следствия. Однако в отличие от традиционного судопроизводства по уголовным делам, в суде с участием присяжных заседателей результаты допросов (как устной речи, «живого слова») существенно превалируют по своей значимости над письменными доказательствами, собранными на досудебной стадии. Искусство судебной речи, в том числе речевое убеждение присяжных в правоте своей позиции, в состязательном судебном процессе ведет к успеху одной из сторон.

Попытаемся разобраться в том, имеется ли речевое взаимодействие между присяжными заседателями и допрашиваемыми лицами, между присяжными заседателями и сторонами обвинения и защиты, а также между присяжными заседателями, с одной стороны, и профессиональным судьей, с другой.

Для ответа на поставленный вопрос потребуется раскрыть три составляющие, одна из которых связана с участием присяжных заседателей в допросе путем постановки вопросов перед допрашиваемым лицом. Присяжные заседатели в соответствии с законом фактически «неговорящие судьи факта». Они не могут задавать вопросы непосредственно допрашиваемым лицам, лишь через председательствующего, профессионального судью. Подтверждением указанного является и сложившаяся судебная практика. Так, одним из оснований отмены оправдательного приговора в отношении Титова в 2003 году Судебной коллегией по уголовным делам Верховного Суда Российской Федерации стало то, что вопреки требованиям закона, присяжные заседатели, не соблюдая письменную форму, непосредственно задали подсудимому 10 вопросов. Судебная коллегия посчитала, что «наличие таких существенных нарушений могло повлиять на правильность принятого присяжными заседателями решения» [Обзор..., URL].

Вопросы от присяжных заседателей в обязательном порядке проходят два этапа:

1) присяжные заседатели сами излагают свои вопросы в письменном виде и подают председательствующему через старшину;

2) эти вопросы формулируются председательствующим и могут быть им отведены как не относящиеся к предъявленному обвинению.

Как видно, на втором этапе председательствующий, профессиональный судья, выступая в роли посредника, в процессе формулирования вопроса может каким-либо образом переосмыслить вопрос и сформулировать по-своему, осознанно или нет субъективно исказив содержательную сторону вопроса. Очевидно, что это может иметь значение для восприятия присяжными полученных ответов и, как следствие, воздействовать на них. Во избежание искажения смысла заданных присяжными вопросов полагаем необходимым обеспечить сочетание дискреционных полномочий судьи по формулированию вопросов с предоставлением сторонам возможности ознакомления с письменными вопросами присяжных заседателей, а также возможности возражения в случае необоснованного их отведения председательствующим судьей. В настоящее время данный момент упущен в законодательстве (см. ч. 4 ст. 335 УпК РФ).

Встречается заслуживающая внимание точка зрения, в соответствии с которой судебный процесс сравнивается с театральным действием, напоминающим спектакль, не в последнюю очередь в связи с четким распределением ролей его участников, известных им заранее. При этом ориентирование происходит непосредственно на присяжных заседателей, которые могут и не обратить внимания на важные для профессионалов обстоятельства. Несомненно, юридическая подготовка (в том числе по использованию лингвистических средств правоприменительной деятельности) профессиональных участников процесса к исполнению своих ролей превосходит знания и навыки тех, кто попал на роль «неговорящих» судей, для которых не предусмотрен законом даже определенный образовательный ценз. Однако их роль связана с каждым профессиональным участником процесса, в том числе председательствующим профессиональным судьей, ограниченным по закону решением лишь процедурных вопросов. Преимущественно роль свидетеля заключается исключительно в предоставлении ответов на поставленные вопросы, а роль государственного обвинителя и защитника, наоборот, сводится к формулированию вопросов и последующему интерпретированию полученных ответов. Роль профессионального судьи связана с обеспечением всех нормативно закрепленных принципов отправления правосудия, в том числе презумпции невиновности, состязательности сторон в судебном разбирательстве; в предоставлении права на реализацию права на защиту, а также с учетом пределов судебного разбирательства. Контроль и структурирование судебного процесса со стороны профессионального судьи реализуются за счет широкого применения метакоммуникативных средств языка, разные комбинации которых организуют судебный дискурс как институционально регламентированный процесс. Судья находится в центре рассуждений, доводов сторон, т.е. судебного процесса как драматического действа, насыщенного вербальными и невербальными ритуальными элементами. Общая обстановка в зале суда, создающая ритуализированное пространство, особая одежда судей (мантия) и их символическая удаленность на некоторой возвышенности от других участников процесса образуют невербальный компонент судебной драмы. Вербальная сторона драмы состоит в использовании судьёй и другими участниками судебного заседания строго 
регламентированных обращений, устойчивых речевых формул, лексики с официально-деловой стилистической окраской и юридической лексики, сложного синтаксиса [Дубровская 2016: 129-130].

Таким образом, несмотря на большую свободу речевых действий в сравнении с иными участниками, речевое участие судьи сконцентрировано на подведении итогов судебного разбирательства, резюме, то есть на произнесении напутственного слова.

Напутственное слово председательствующего судьи, при котором результаты допросов передаются присяжным заседателям, относится к другой составляющей ответа на поставленный в статье вопрос. Судопроизводство с участием присяжных заседателей обеспечивается большим количеством участников судебного разбирательства, и зачастую звучит множество монологов, рассказов, речей участников процесса. Ключевой фигурой в центре выступает профессиональный судья. Поэтому от его языковой и, шире, коммуникативной компетенции зависит эффективность протекающего полифоничного коммуникативного процесса.

Перед удалением присяжных заседателей в совещательную комнату для вынесения вердикта председательствующий по делу судья в своем монологе - напутственном слове - подводит итоги, чем фактически завершает все судоговорение в процессе. В напутственном слове профессиональный судья напоминает присяжным заседателям в том числе об исследованных в суде доказательствах как уличающих подсудимого, так и оправдывающих его, не выражая при этом своего отношения к этим доказательствам и не делая выводов из них. Обратим внимание на использованный законодателем термин «напоминает» (п. 3 ч. 3 ст. 340 УПК РФ). На наш взгляд, средства юридической техники здесь не применены должным образом. Результатом становится неточность определения пределов и способа осуществления дискреционных полномочий профессионального судьи.

Напоминание - это текст, представляющий собой извещение, уведомление, обращенное к кому-либо. с целью освежить в чьей-либо памяти что-либо, заставить вспомнить о ком-, чем-либо [Бабенко URL]. Cудебная практика сводится к тому, что профессиональный судья по существу пересказывает содержание доказательств, в том числе показания допрошенных лиц, как свидетелей, так и потерпевших. Проблема заключается в невозможности достаточно четко передать в форме пересказа результат допроса, как свидетелей, так и потерпевших, поскольку изложение «живого» диалога всегда затруднено, в сознании содержание показаний закрепляется субъективно, а в пересказе часть информации может быть утрачена.

Таким образом, судья фактически систематизирует общедоступные фразы и выражения, которыми пользовалось допрашиваемое лицо, при этом отдельные фрагменты полученной информации субъективно истолковываются с учетом восприятия самим профессиональным судьей. Соответственно, одни аспекты приобретают существенное значение и выделяются, другие - уходят в тень. Результат допроса свидетелей ведет к формированию определенной позиции как защиты, так и обвинения. Представляется, что в целях повышения эффективности восприятия присяжными заседателями доводимой до них в напутственном слове информации, касающейся напоминания содержания допросов, с целью формирования их внутреннего убеждения требуется уточнение требований к содержанию напутственного слова председательствующего путем внесения изменений в п. 1 ч. 3 ст. 340 УПК РФ.

Третья составляющая ответа на поставленный в статье вопрос связана с формированием вопросного листа, содержанием вопросов, которые ставятся перед присяжными заседателями.

В вопросном листе по каждому из деяний в обязательном порядке ставятся следующие вопросы:

1) доказано ли, что деяние имело место;

2) доказано ли, что это деяние совершил подсудимый.

В соответствии с положениями статьи 339 УПК РФ вопросы ставятся в понятных присяжным заседателям формулировках.

Сложным как для теории, так и для судебной практики остается значение категории выражения «понятных формулировках», а также использование вопросительных предложений вместо вопросов, на которые присяжные должны дать ответы. Судебная практика свидетельствует о том, что зачастую вместо вопросов, как регламентировано законом, присяжные имеют дело с длинными вопросительными предложениями с частицей «ли», в которых по существу заключается информирование, суждение об обвинении, либо просто утверждения из обвинительного заключения, переписанные в вопросительной форме, но при этом чрезмерно перегруженные. При этом вопросительные предложения в зависимости от требуемого ответа могут носить различный характер: утвердительный, отрицающий, побудительный и риторический. Искажает ли использование по существу вопросительного предложения смысл слова «вопрос» или является вполне допустимым? Бесспорно, содержание вопросного листа по сути влияет на итоговое решение по делу. Перегруженность фактических данных, перенесенных из обвинительного заключения в вопросный лист, требует от присяжных заседателей их полного осмысления для верного ответа. Такое осмысление напрямую согласуется с выражением «понятные формулировки» в поставленном вопросе или вопросительном предложении. Нередко, в целом, вопросный лист представляет собой нагромождение фактических данных, сложно изложенной информации об обстоятельствах обвинения. Цель понятна предопределить описание преступного деяния в будущем судебном приговоре.

Как свидетельствует судебная практика, при рассмотрении Ленинградским областным судом [Архив..., 2019] каждого из поступивших в 2018 году трёх уголовных дел о бандитизме подобная громоздкость формулирования вопросного предложения о доказанности деяния привела к отрицательному ответу на него присяжными заседателями, полагаем, в том числе, и по причине перегруженности и непонятности. Приведем пример (текст по указанной категории уголовных дел): 
«Доказано ли, что в таком-то году, но не позднее такого-то числа, в таком-то месте была создана группа из _ (кол-во) человек для нападения на граждан и завладения их имуществом; для вооружения группы такого-то числа, месяца и года был приобретен пригодный для стрельбы пистолет таких-то марки и калибра, и не менее ___(кол-во) патронов к нему; помимо этого группа была вооружена: начиная с такой-то даты таким-то пистолетом, пригодным для стрельбы, и __(кол-во) патронами к нему; с такой-то даты - неустановленным пистолетом, использовавшимся со сменным магазином и __(кол-во) самодельными патронами такого-то калибра; с такой-то даты - самовзводным пистолетом такого-то калибра с ___(кол-во) патронами; создателем и руководителем группы, а также её участниками разрабатывались планы совершения нападений на граждан, осуществлялся сбор информации о будущих жертвах, об уровне их защищенности, об их материальном положении; совершались нападения на граждан с требованием денег под угрозой применения насилия; при этом для осуществления своих целей участники группы использовали автомобили__(кол-во) таких-то марок (перечисление марок машин и номеров) с такими-то номерами?»

Приведенный пример свидетельствует об отсутствии интеграции лингвистических и юридических положений, недоступности и непонятности постановки вопроса простому гражданину, не обладающему юридическими познаниями.

Также, если постановка первого вопроса о доказанности имевшего места деяния, хотя и громоздко, но описывает фактические обстоятельства действия или бездействия, повлекшие за собой общественно опасные последствия, то постановка второго вопроса требует от присяжных заседателей правовой оценки, поскольку зачастую формулируется следующим образом: «Если на первый вопрос дан утвердительный ответ, то доказано ли, что описанное в первом вопросе деяние совершил подсудимый...?» и т.д.

Обращает на себя внимание, что с точки зрения юридической значимости содержание термина «деяние» недоступно обычному носителю языка, чаще всего не имеющему ни юридического, ни лингвистического образования. Употребление термина «деяние» в вердикте коллегии присяжных заседателей приводит к приданию ему правового значения. В такой ситуации исходный текст описания фактических обстоятельств отчасти «переводится» на юридический язык. Хотя формально это и не противоречит требованиям закона, реально юридическое понимание термина «деяние» остается недоступно присяжным заседателям, в связи с чем представляется необходимым адаптировать указанный термин. К примеру, можно использовать другой вариант постановки второго вопроса, который нередко предлагает судебная практика: «Если на первый вопрос дан утвердительный ответ, то доказано ли, что описанные в нем действия (именно действия, а не деяние - прим. авт.) совершил подсудимый...?» и т.д.

Приведенный вариант в большей мере обеспечит адекватность понимания присяжными заседателями поставленного вопроса, что согласуется с положениями статьи 339 УПК РФ о том, что вопросы ставятся в понятных присяжным заседателям формулировках. Эта же позиция следует из разъяснений, изложенных в пункте 29 постановления Пленума Верховного Суда Российской Федерации от 22.11.2005 № 23 «О применении судами норм Уголовно-процессуального кодекса Российской Федерации, регулирующих судопроизводство с участием присяжных заседателей», где отмечено, что не могут ставиться отдельно либо в составе других вопросы, требующие от присяжных заседателей собственно юридической оценки при вынесении присяжными заседателями своего вердикта.

Анализ текста уголовно-процессуального закона и теоретических источников позволяет сделать вывод о том, что, будучи предназначенным для урегулирования общественных отношений в сфере публичного права, где вероятность ограничения гарантированных Конституцией Российской Федерации прав и свобод человека очень высока, УПК РФ на сегодняшний день не в полной мере соответствует требованиям юридической техники [Петухов 2016: 61]. Решением этой проблемы может стать рассмотрение законодателем давно высказываемых предложений о необходимости решения присяжными заседателями единственного вопроса о виновности или невиновности подсудимого, с отнесением описания и правовой оценки фактических обстоятельств преступного деяния к компетенции профессионального судьи.

\section{Литература}

1. Архив Ленинградского областного суда, уголовные дела №2-8/18, 2-32/18, 2-5/2019.

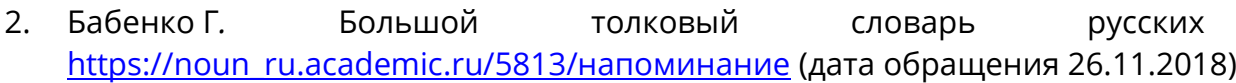

3. Галяшина Е.И. Феномен судебного речеведения: Наука - экспертиза - обучение // Вестник Университета имени О.Е. Кутафина. 2015. №12.

4. Дубровская Т.В. Судья: речевое поведение в судебном дискурсе // Дискурс-Пи, 2016. №1.

5. Казанцев С.М. Суд присяжных в России: Громкие уголовные процессы 1864-1917 гг. СПб., 1991.

6. Обзор по делам, рассмотренными судами с участием присяжных заседателей в 2003 году, утвержденного Судебной коллегией по уголовным делам ВС РФ 01.06.2004 г. URL: http://ппвс.pф/2004/obzor-sudebnoy-praktikivs-rf/2004.06.01-prisyajnye.html (дата обращения 26.11.2018).

7. Первый постсоветский суд присяжных. URL: https://pravo.ru/process/view/24686/ (дата обращения 26.11.2018)

8. Петухов Е.Н. Коррекционное толкование отдельных положений уголовно-процессуального закона как средство уяснения их точного смысла и правильного применения // Юрислингвистика, 2016. № 5. 


\section{References}

1. Arkhiv Leningradskogo oblastnogo suda. (2019). Ugolovnye dela 2-8/18, 2-32/18, and 2-5/2019 (in Russian).

2. Babenko G. Bol'shoi tolkovyi slovar' russkikh sushchestvitel'nykh. (2009). Available from: https://noun_ru.academic.ru/5813/напоминание (in Russian).

3. Dubrovskaya, T.V. (2016). Judge: speech behavior in judicial discourse [Sud'ya: rechevoe povedenie $v$ sudebnom diskurse]. Diskurs-Pi - Discourse P, 1 (in Russian).

4. First Post-Soviet jury trial. (2018). [Pervyj postsovetskij sud prisyazhnyh]. Available from: https://pravo.ru/process/view/24686/ (in Russian).

5. Galyashina, E.I. (2015). The phenomenon of judicial speech: Science-expertise-training [Fenomen sudebnogo rechevedeniya: Nauka-ehkspertiza-obuchenie]. Vestnik Universiteta imeni O.E. Kutafina - Bulletin of the University of O.E. Kutafin, 12 (in Russian).

6. Kazancev, S.M. (1991). Jury trial in Russia: high-Profile criminal trials of 1864-1917 [Sud prisyazhnyh v Rossii: Gromkie ugolovnye processy 1864-1917]. Saint Petersburg (in Russian).

7. Obzor po delam, rassmotrennymi sudami s uchastiem prisyazhnykh zasedatelei v 2003 godu. (2004). Sudebnaya kollegiya po ugolovnym delam VS RF 01.06.2004. Available from: http://ppvs.rf/2004/obzor-sudebnoy-praktiki-vsrf/2004.06.01-prisyajnye.html/ (in Russian)

8. Petuhov, E.N. (2016). Correctional interpretation of certain provisions of the criminal procedure law as a means of understanding their exact meaning and correct application [Korrekcionnoe tolkovanie otdel'nyh polozhenij ugolovnoprocessual'nogo zakona kak sredstvo uyasneniya ih tochnogo smysla i pravil'nogo primeneniya]. Yurislingvistika Legal linguistics, 5 (in Russian).

\section{Citation:}

Зейдлиц Е.Г. Некоторые особенности допроса в суде с участием присяжных заседателей с точки зрения юрислингвистики.

// Юрислингвистика. - 2019. - 11. - С. 5-10.

Zeidlits, E.G. (2019). Some features of interrogation in trial jury according to legal linguistics. Legal Linguistics, 11, 5-10. 